\title{
Frequency Reconfigurable Antenna using PIN Diodes
}

\author{
S. Praveena, Sunakar Prusty
}

\begin{abstract}
With the increase in wireless applications, there is a need for compact antennas that adapt their behavior with changing system requirements or environmental conditions. Here adapt implies the antenna should be able to alter operating frequencies, impedance bandwidths, polarizations, radiation patterns. These all features are provided by the "Reconfigurable antenna". The important feature of reconfigurable antenna is that, they provide the same throughput as a multi-antenna system. A compact frequency reconfigurable antenna is designed with the aid of Ansoft HFSS that provides multiple frequency bands. This is achieved by using electrical switches such as PIN diodes. Depending on state of switches different operating frequencies are obtained. The switches placed on the antenna elements are powered wirelessly by the antenna itself. The design, geometries and simulation results of a frequency reconfigurable antenna are presented in this report. Further advancements are to be done for this structure to achieve polarization and radiation pattern re-configurability.
\end{abstract}

Key words- Wireless Communication system, Frequency Reconfigurable, Microstrip feed line, PIN diode

\section{INTRODUCTION}

With the increasing demand for reliable wireless communications there is a need to use the electro-magnetic spectrum efficiently. Consider two general application areas, single-element scenarios and array scenarios. Single element scenarios refer to antennas such as antenna used in portable wireless devices such as cellular telephone, a personal digital assistant or a laptop computer. Single antennas used in these devices can be monopole or microstrip based and may or may not have multiple frequency capabilities. Some devices use more than one antenna for diversity reception. Here diversity reception means increasing the probability of receiving the required signal. Even though we use multiple antennas in these devices, only one antenna is used for transmission. Hence the other antennas except antenna used for transmission are of no use rather that results in unwanted use of electromagnetic spectrum. The weakest part of the bidirectional communication link is the transmission from portable device to the base station or some other access point. Portable communication imposes the usage of high power and restrictions on cost and size. In such situations antenna re-configurability provides lot of advantages. In the array scenarios, there is a limitation on the frequency bandwidth. In such situations addition of re-configurability to antenna arrays results in wider frequency bandwidths.

Revised Manuscript Received on December 15, 2019.

S. Praveena, Department of Electronics and Communication, Vignan's Foundation for Science, Research and Technology

Guntur, Andhra Pradesh, India. psirimilla@gmail.com

Sunakar Prusty, Department of Electronics and Communication,Vignan's Foundation for Science, Research and Technology Guntur, Andhra Pradesh, India. Sunakar175@gmail.com
In general, reconfigurable means to change or arrange something. In the similar way when it comes to the context of antennas, it is the ability to change the radiator's fundamental operating characteristics through some means of switches such as mechanical, electrical etc. which in layman's terms means ability to tune the antenna to account for the new environment. To achieve beam forming and beam steering phasing of signals between elements in an antenna array will be done. But it does not mean that it provides re-configurability because antennas fundamental operating characteristics do not change in this case. Hence re-configurability means capacity to change fundamental operating characteristics. For implementing reconfigurable antennas micro-strip patch antennas are the very best structures since they provide numerous advantages compared to conventional antennas.

To obtain re-configurability in an antenna, switching is required. Diodes such as PIN, FET serves this purpose. PIN diode is considered as a best switching device as compared to other diodes. PIN diode is a current controlled device. It provides the few advantages over other switching devices. PIN diodes have the ability to control large RF signal power while using much smaller levels of control power. PIN diodes are less susceptible to electrostatic discharge (ESD) damage. The off capacitance of PIN diodes is a function of reverse voltage. The more negative the voltage, the less the capacitance.

Frequency re-configurability can be achieved by modifying the physical and electrical dimensions of antenna. Polarization re-configurability can be achieved by introducing perturbation elements into the radiating components of the structure or by altering the feeding networks. Radiation pattern re-configurability can be achieved by rerouting the current through switches or by using variable loading to change the current behavior on parts of the antenna or by adding variable parasitic elements to alter the performance of the driven element.

\section{LITERATURE SURVEY}

In [1], the basics concepts of patch antennas are described. Basic concepts explained in this paper include basic working principle of patch antenna, fundamental specifications of patch antennas, various feed types and their usage according to the application, behavior in the higher modes, stacked patches and their feeding. In this paper, as an example, a simple rectangular, half wave long, probe-fed patch operating in fundamental mode is considered. And it clearly describes the effect of width of the patch on the input impedance. In [2], different types of solid state switches and their performance specifications is described.

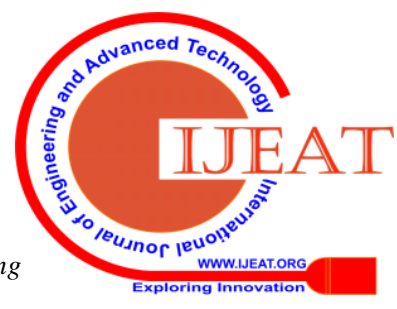


As PIN diode is used for re-configurability in this project, knowing the operation and their behavior is important. Hence referring to paper [2], the behavior of PIN diodes in forward and reverse bias and their equivalent circuits can be understood that are needed to put while designing the reconfigurability antenna. In [3], a frequency reconfigurable antenna is designed that is capable of switching between single, dual, and triple bands. Depending on state of the diodes, different bands can be obtained. The PIN diodes are placed in the dipole arms in the design. The triple bands that are achieved in this design are $2.4 \mathrm{GHz}, 3.5 \mathrm{GHz}$, and 5.2 $\mathrm{GHz}$ that enables the system to support Bluetooth, WiMAX, and WLAN systems respectively. In [4], a frequency reconfigurable antenna is designed that is useful for S-band and C-band applications. Three slots with two switches in the ground are present in the design. This antenna is able to produce three different frequency bands at $3.06 \mathrm{GHz}, 3.26$ $\mathrm{GHz}(\mathrm{S}$-band) and 4.27 GHz(C-band).

\section{AnTENna STRUCTURE}

There are many wireless applications such as WiFi(2.45GHz), WiMAX $(3.5 \mathrm{GHz}), \quad$ GSM(1.71-2.17GHz), PCS(1.85-1.99GHz),

Bluetooth $(2.4-2.48 \mathrm{GHz})$,

WLAN $(5.4 \mathrm{GHz})$ etc. A 4 shaped frequency reconfigurable antenna is designed that finds applications such as Wi-Fi, C-band, Personal Communication Systems, GSM. The resonant frequencies in this antenna are reconfigured by using PIN diodes.

The 4 shaped monopole frequency reconfigurable antenna is printed on a FR-4 substrate(dielectric) that has a thickness of $1.6 \mathrm{~mm}$ and with dielectric constant of 4.4 and loss tangent of 0.019 . Ground plane thickness is considered as $0.035 \mathrm{~mm}$. The ground plane is truncated to widen the bandwidth. Ground plane dimensions are taken as $18 \times 35 \mathrm{~mm}^{2}$. Substrate dimensions are taken as $40 \times 35 \mathrm{~mm}^{2}$. The remaining dimensions of the antenna after calculations were found as

$\mathrm{W}=3 \mathrm{~mm}, \quad \mathrm{~L} 1=7 \mathrm{~mm}, \quad \mathrm{Lf}=18 \mathrm{~mm}, \mathrm{~L} 2=4.5 \mathrm{~mm}, \quad \mathrm{~L} 3=2 \mathrm{~mm}$, $\mathrm{SW} 1=\mathrm{SW} 2=\mathrm{SW}=1 \mathrm{~mm}, \mathrm{~L} 5=18 \mathrm{~mm}, \mathrm{~L} 4=3 \mathrm{~mm}$

Two PIN diode switches are incorporated in the design. In the design, $1 \mathrm{~mm}$ is reserved for each of the switch. Structure of the antenna with all the dimensions is shown in the figure 1 .

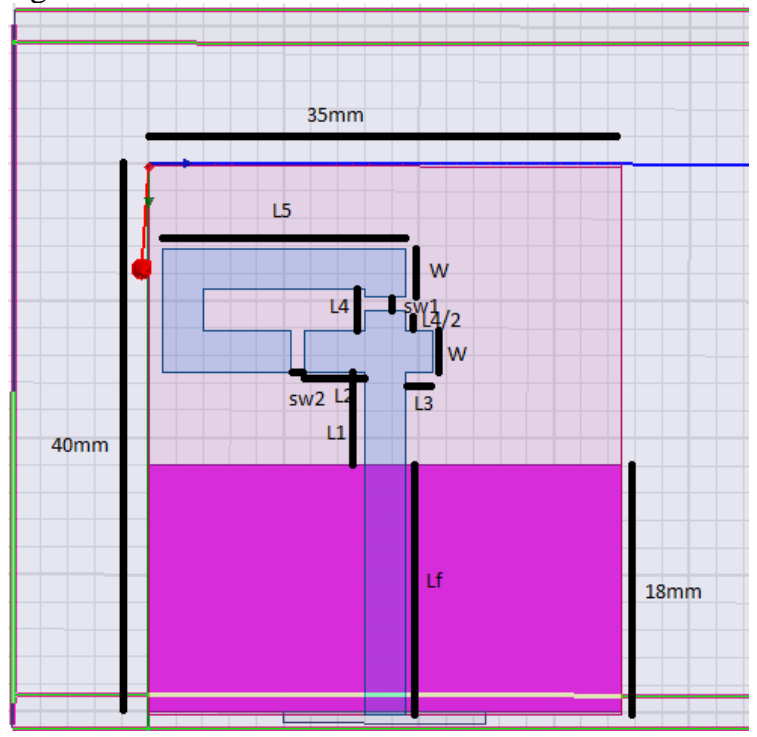

Fig.1 Antenna Structure

\section{Simulation RESUlts AND Discussions}

\section{Case (i) $S 1$ on and $S 2$ on}

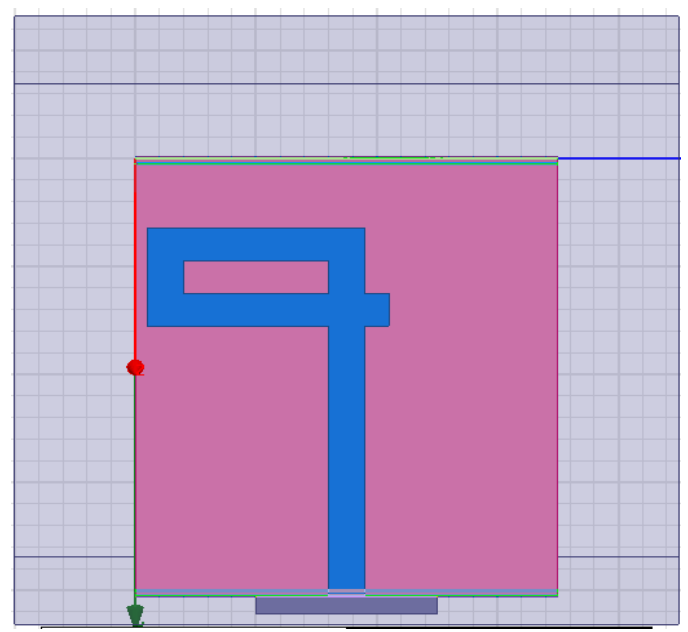

Fig. 2 Antenna Structure with S1 on and S2 on

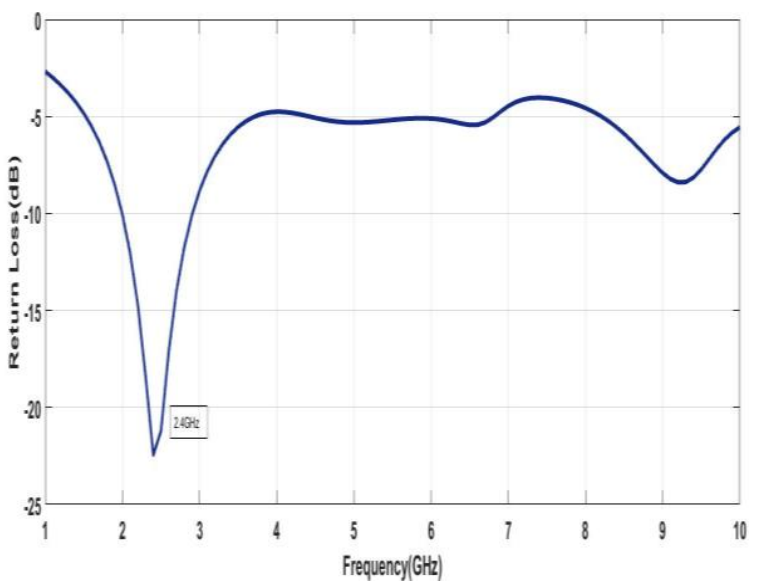

Fig. 3 S11 graph

When both the switches are ON, the monopole antenna is observed to resonate at $2.4 \mathrm{GHz}$ with a return loss of $-23 \mathrm{~dB}$ From the theory of transmission line model, the effective length for $2.4 \mathrm{GHz}$ is $\mathrm{L} 1+(2 * \mathrm{~L} 5)+(2 * \mathrm{~L} 4)=49 \mathrm{~mm}$. VSWR is observed to be 1.16 which is less than 1.5 , hence antenna match is considered very good. It is worth to tell that in this mode of switching, antenna is matched to the feed line impedance i.e. a better impedance matching of 44ohms at 2.4GHz. Antenna in this switching mode is useful for Bluetooth(2.4-2.48GHz) and $\mathrm{Wi}-\mathrm{Fi}(2.45 \mathrm{GHz})$ applications.

\section{Case (ii) S1 off and S2 off}

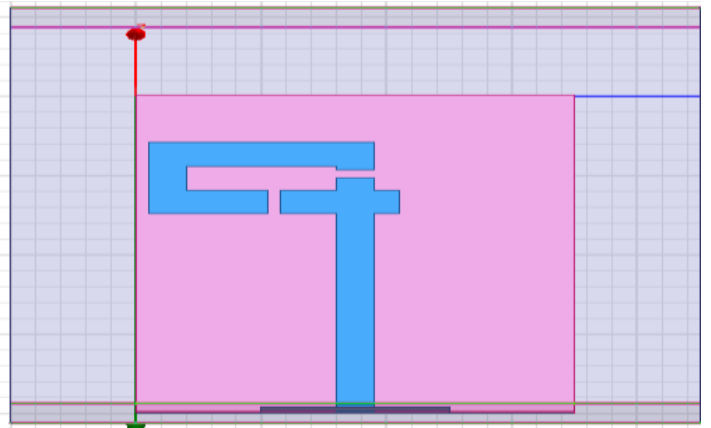

Fig. 4 Antenna Structure with S1 off and S2 off

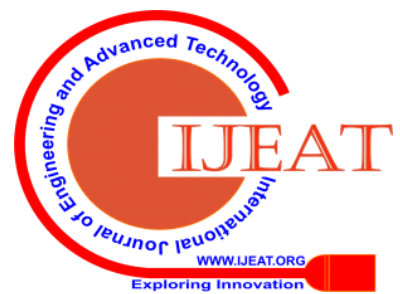




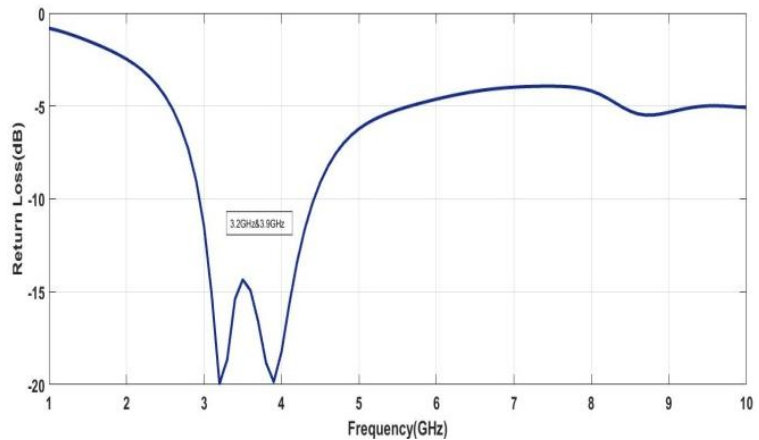

Fig. 5 S11 graph

When both the switches are OFF, the monopole antenna is observed to produce an ultra wideband with a return loss of $-20 \mathrm{~dB}$. From the theory of transmission line model, the effective length is given as $\mathrm{L} 1+\mathrm{L} 2+\mathrm{L} 3+(2 * \mathrm{~W})+(\mathrm{L} 4 / 2)$ $=22 \mathrm{~mm}$. VSWR is observed to be 1.22 which is less than 1.5 , hence antenna match is considered very good. It is worth to tell that in this mode of switching, antenna is matched to the feed line impedance i.e. a better impedance matching of $57 \mathrm{ohms}$ at $3.5 \mathrm{GHz}$. Since antenna in this switching mode provides UWB, it can be used for noncooperative radar imaging, precision locating and tracking applications.

\section{Case (iii) S1 on and S2 off}

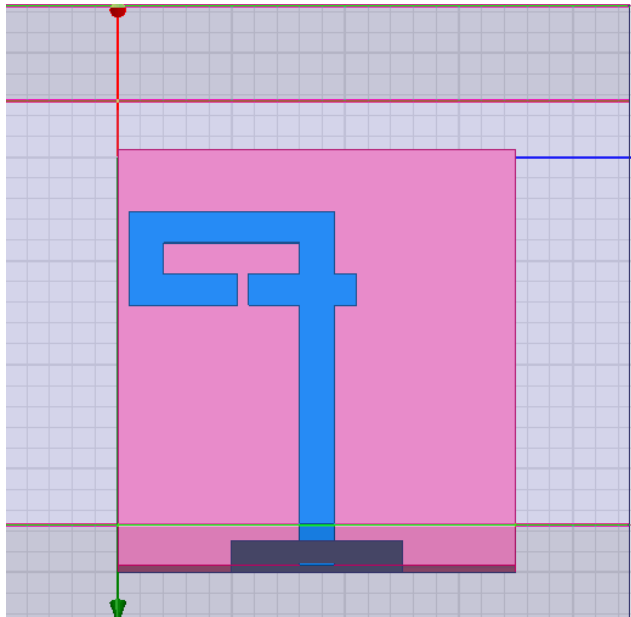

Fig. 6 Antenna Structure with S1 on and S2 off

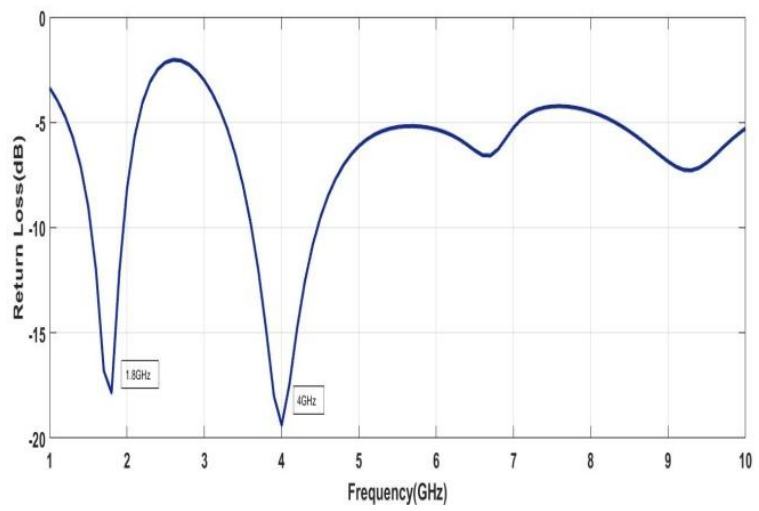

Fig. 7 S11 graph

When the switch $\mathrm{S} 1$ is $\mathrm{ON}$ and $\mathrm{S} 2$ is OFF, the monopole antenna is observed to resonate at $1.8 \mathrm{GHz}$ and $4 \mathrm{GHz}$ with a return loss of $-18 \mathrm{~dB}$ and $-19 \mathrm{~dB}$ respectively. From the theory of transmission line model, the effective length for the frequency $1.8 \mathrm{GHz}$ is $\mathrm{L} 1+(2 * \mathrm{~L} 4)+(2 * \mathrm{~L} 5)+(2 * \mathrm{~W})-\mathrm{L} 2-$ $\mathrm{SW}=49.5 \mathrm{~mm}$ and the effective length for the frequency $4 \mathrm{GHz}$ is $\mathrm{L} 1+\mathrm{L} 2+(2 * \mathrm{~W})=17.5 \mathrm{~mm}$. VSWR is observed to be 1.29 and 1.24 for the frequencies $1.8 \mathrm{GHz}$ and
4GHzrespectively(both less than 1.5). In this mode of switching, impedance matching of $390 \mathrm{ohms}$ and $59 \mathrm{ohms}$ is observed at $1.8 \mathrm{GHz}$ and $4 \mathrm{GHz}$ respectively. Antenna in this switching mode is useful for GSM(1.71-2.17GHz) and Cband(4-8GHz) applications.

\section{Case (iv) S1 off and S2 on}

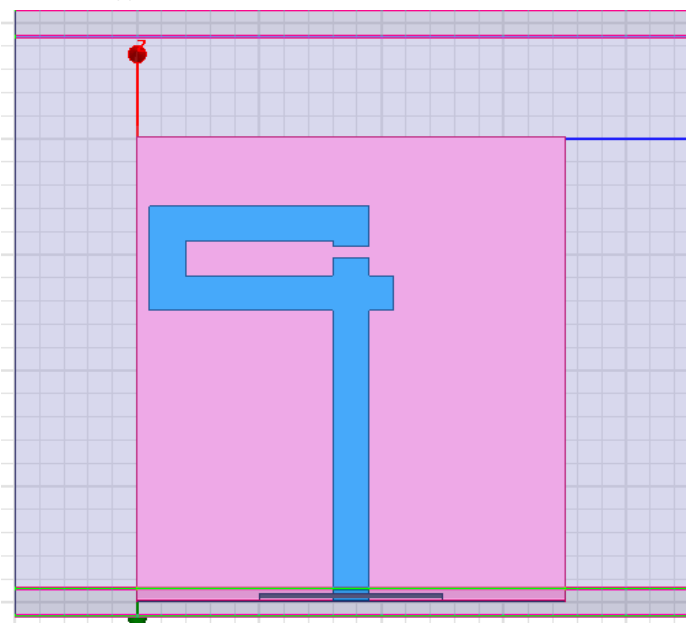

Fig. 8 Antenna Structure with S1 off and S2 on

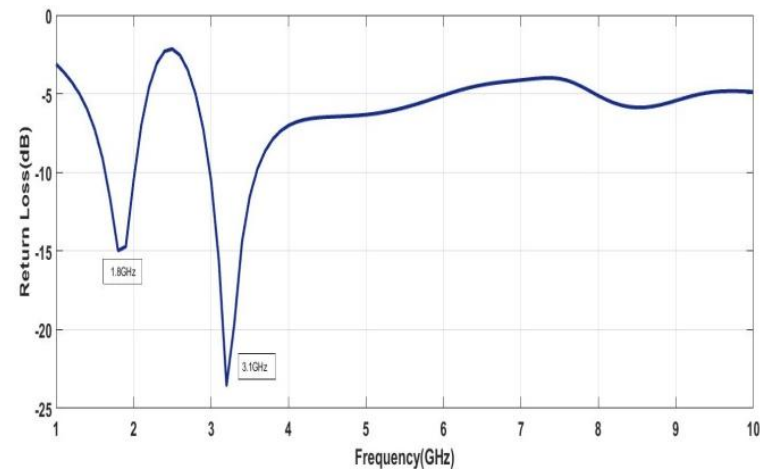

Fig. 9 S11 graph

When the switch S1 is OFF and S2 is ON, the monopole antenna is observed to resonate at $1.8 \mathrm{GHz}$ and $3.1 \mathrm{GHz}$ with a return loss of $-15 \mathrm{~dB}$ and $-24 \mathrm{~dB}$ respectively. From the theory of transmission line model, the effective length for the frequency $1.8 \mathrm{GHz}$ is $\mathrm{L} 1+\mathrm{L} 4+\mathrm{W}+(2 * \mathrm{~L} 5)+0.5 \mathrm{~mm}$ $=49.5 \mathrm{~mm}$ and the effective length for the frequency $3.1 \mathrm{GHz}$ is $\mathrm{L} 1+(\mathrm{L} 4 / 2)+(2 * \mathrm{~W})=14.5 \mathrm{~mm}$. VSWR is observed to be 1.43 and 1.14 for the frequencies $1.8 \mathrm{GHz}$ and $3.1 \mathrm{GHz}$ respectively(both less than 1.5). In this mode of switching, impedance matching of $34 \mathrm{ohms}$ and $53 \mathrm{ohms}$ is observed at $1.8 \mathrm{GHz}$ and $4 \mathrm{GHz}$ respectively. Antenna in this switching mode is useful for PCS(1.85-1.99GHz) applications.

\section{Simulation Vs HARdWARE RESUlts}




\section{Frequency Reconfigurable Antenna using PIN Diodes}

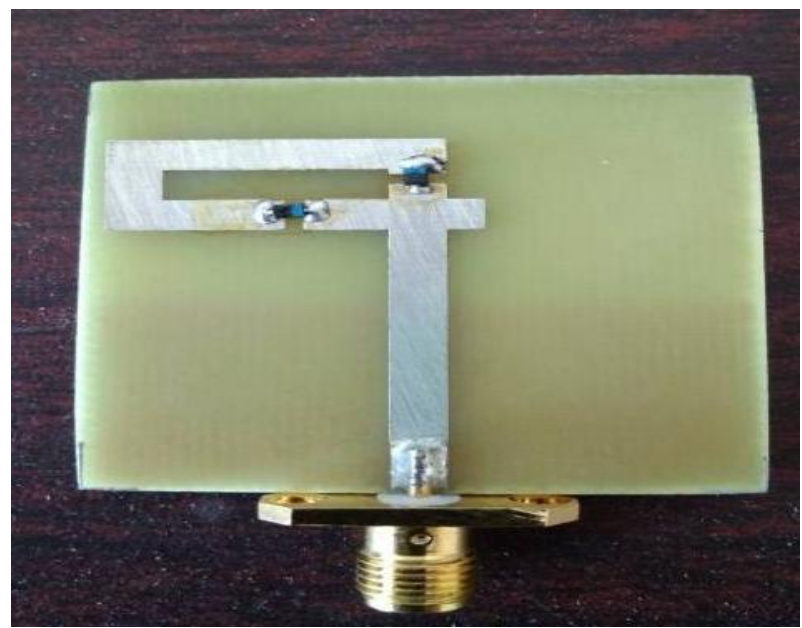

Fig. 10 Fabricated Antenna

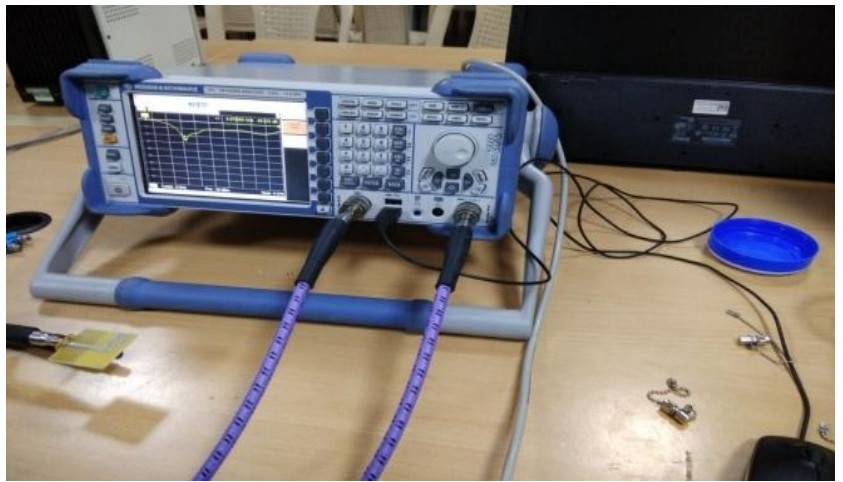

Fig. 11 Testing using Vector Network Analyzer

The proposed antenna is fabricated and it is tested using vector network analyzer as shown in figure10 and figure 11.

Case (i) S1 on and S2 on

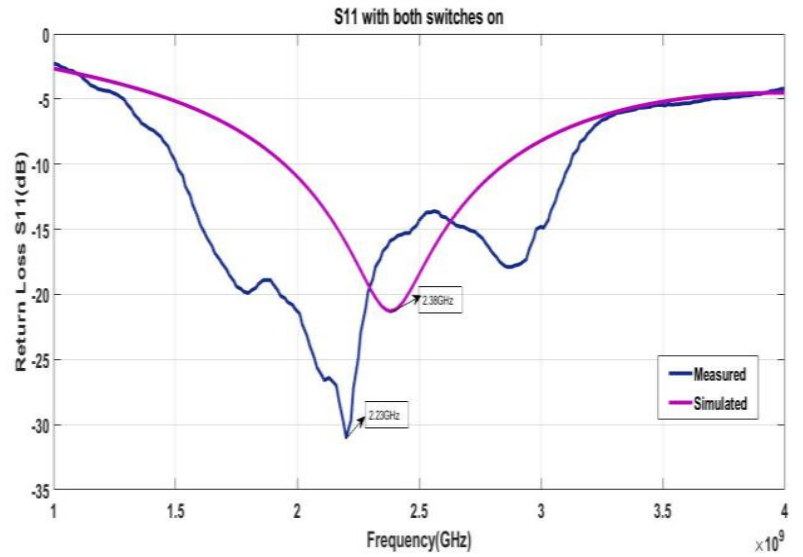

Fig. 12 S11 graph

With switches in the simulation, the resonant frequency is $2.38 \mathrm{GHz}$. When measured, it is observed to be $2.23 \mathrm{GHz}$ where the simulation and practical results are perfectly matched.

Case (ii) S1 off and S2 off

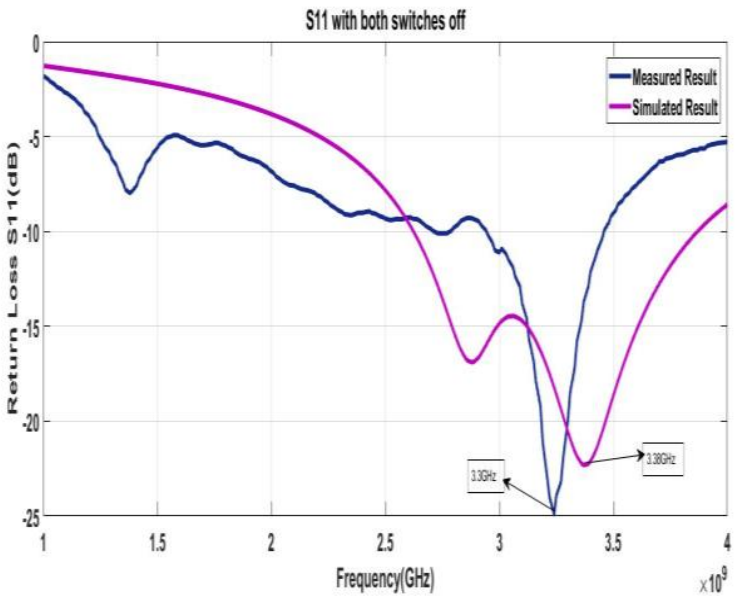

Fig. 13 S11 graph

With switches in the simulation, the resonant frequency is $3.38 \mathrm{GHz}$. When measured, it is observed to be $3.3 \mathrm{GHz}$ where the simulation and practical results are perfectly matched.

\section{Case (iii) S1 on and S2 off}

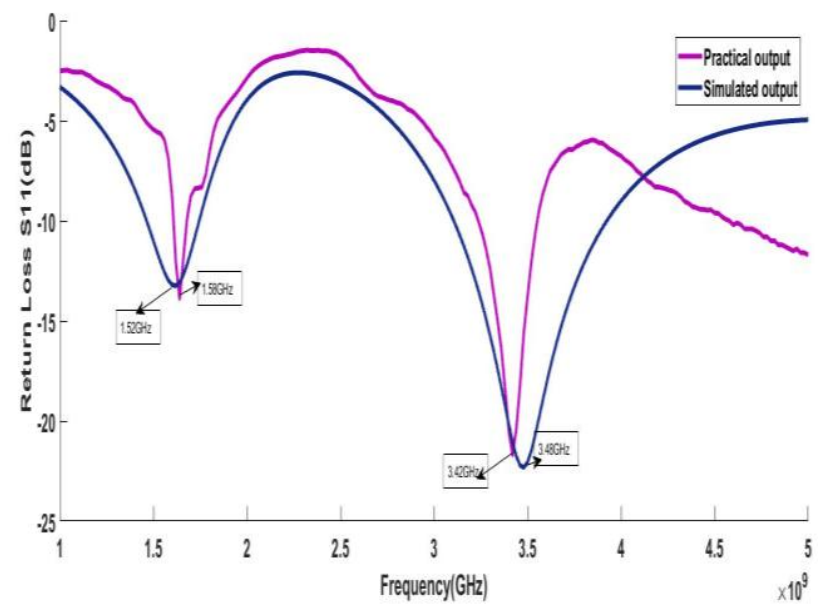

Fig. 14 S11 graph

With switches in the simulation, dual band is achieved with the resonant frequencies at $1.52 \mathrm{GHz}$ and $3.48 \mathrm{GHz}$. When measured, it is observed to be $1.58 \mathrm{GHz}$ and $3.42 \mathrm{GHz}$ where the simulation and practical results are perfectly matched.

Case (iv) S1 off and S2 on

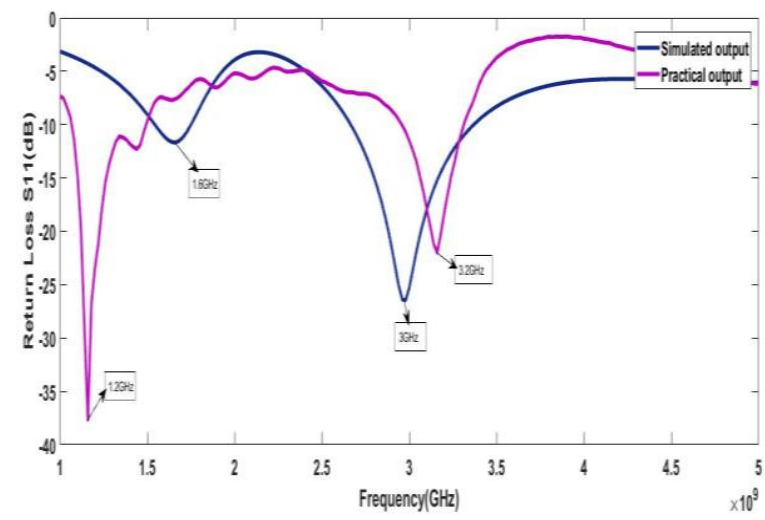

Fig. 15 S11 graph

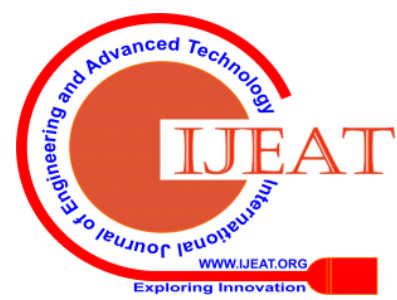


With switches in the simulation, dual band is achieved with the resonant frequencies at $1.6 \mathrm{GHz}$ and $3 \mathrm{GHz}$. When measured, it is observed to be $1.2 \mathrm{GHz}$ and $3.2 \mathrm{GHz}$ where the simulation and practical results are almost matched.

\section{CONCLUSION}

Achieved frequency bands for different states of the switches without incorporating switches (i.e. direct connection of patches is done instead of switches) in the simulation are listed in table: 1.

\section{Table:1}

\begin{tabular}{|l|l|l|l|}
\hline S1 & S2 & $\begin{array}{l}\text { Frequency } \\
\text { Bands }\end{array}$ & $\begin{array}{l}\text { Resonant } \\
\text { Frequencies }\end{array}$ \\
\hline on & on & Single band & $2.4 \mathrm{GHz}$ \\
\hline off & off & Wide band & $3.5 \mathrm{GHz}$ \\
\hline on & ff & Dual band & $1.8 \mathrm{GHz} \& 4 \mathrm{GHz}$ \\
\hline off & on & Dual band & $1.8 \mathrm{GHz} \& 3.1 \mathrm{GHz}$ \\
\hline
\end{tabular}

After incorporating switches in the simulation, the achieved frequency bands are listed in table:2.

Table:2

\begin{tabular}{|l|l|l|l|}
\hline S1 & S2 & $\begin{array}{l}\text { Frequency } \\
\text { Bands }\end{array}$ & $\begin{array}{l}\text { Resonant } \\
\text { Frequencies }\end{array}$ \\
\hline on & on & Single band & $2.38 \mathrm{GHz}$ \\
\hline off & ff & Single band & $3.38 \mathrm{GHz}$ \\
\hline on & off & Dual band & $1.52 \mathrm{GHz} \& 3.48 \mathrm{GHz}$ \\
\hline off & on & Dual band & $1.6 \mathrm{GHz} \& 3.0 \mathrm{GHz}$ \\
\hline
\end{tabular}

\section{REFERENCES}

1. D. Orban and G.J.K. Moernaut, "The basics of patch antennas", Orban microwave products, White Paper, 2005.

2. Keysight technologies, "Understanding RF/Microwave solid state switches and their applications", Literature number 5989-7618EN, October 2007.

3. IzniHusna Idris, Mohamad rijal Hamid, MohdHaizal Jamaluddin, Mohamad kamal A. Rahim, James R. Kelly and Huda A. Majid, "Single, dual, and triple band frequency reconfigurable antenna", Radio Engineering 23(3): 805-811, Vol. 23, No. 3, September 2014.

4. Babu Lal Sharma, Girish Parmar and Mithilesh Kumar, "Design of frequency reconfigurable Microstrip patch antenna for S-band and C-band applications", $20154^{\text {th }}$ International Conference onReliability, Infocom Technologies and Optimization, IEEE Conferences, pages 1-3, 2015. 